\title{
Análise da acessibilidade no centro de tratamento da criança com câncer de um hospital universitário
}

\author{
Laura Bianchetti Galvan (1D, Andreisi Carbone Anversa (D), \\ Alexandra Ramos Moreira da Silva (D), Lucielem Chequim da Silva
}

Departamento de Terapia Ocupacional, Universidade Federal de Santa Maria - UFSM, Santa Maria, RS, Brasil.

\begin{abstract}
Resumo: Introdução: O presente artigo discorre sobre a acessibilidade física e suas possíveis influências frente aos usuários de um serviço oncológico. Através do olhar da terapia ocupacional, considera-se esse um aspecto importante diante do processo de reabilitação desses indivíduos, visto que a estrutura arquitetônica e a organização do meio podem constituir-se como facilitadores ou barreiras, influenciando o fazer humano. Objetivo: Identificar quais são as reais condições de acessibilidade física para os usuários no Centro de Tratamento da Criança com Câncer (CTCriaC) do Hospital Universitário de Santa Maria (HUSM). Método: Essa pesquisa possui abordagem quantitativa, a qual se constituiu por uma avaliação física de áreas de livre circulação do HUSM, assim como do espaço compreendido pelo CTCriaC, quanto à aplicabilidade da Norma Brasileira: ABNT NBR 9050, e da Resolução - RDC $\mathrm{n}^{\circ}$ 50. Resultados: Os resultados foram apresentados em forma estatística e descritiva, sendo avaliados 266 itens, dos quais apenas 30,07\% apresentavam-se adequados. Entre esses, 76,92\% dos itens correspondentes à rota de acesso externa apresentavam-se inadequados, bem como 63,97\% daqueles relacionados à rota de acesso interna do HUSM ao CTCriaC e ambiente do mesmo. $80 \%$ e 79,03\% dos itens correspondentes aos quartos e sanitários do CTCriaC apresentaram-se inadequados, respectivamente. Conclusão: Constatou-se que os ambientes avaliados se encontravam, em sua maioria, inadequados devido à presença de barreiras arquitetônicas, podendo acarretar consequentes prejuízos às pessoas que apresentam mobilidade reduzida por quaisquer motivos.
\end{abstract}

Palavras-chave: Oncologia, Terapia Ocupacional, Estruturas de Acesso, Acesso aos Serviços de Saúde.

\section{Analysis of physical accessibility in the treatment center for children with cancer of the university hospital}

\begin{abstract}
Introduction: This article discusses physical accessibility and possible influences across users of an oncology service. Through the eyes of Occupational Therapy, we consider this as an important aspect before the rehabilitation process of these individuals, as the architectural structure and organization of the environment can be constituted as facilitators or barriers, influencing the human doing. Objective: To identify what the actual conditions of physical accessibility for users in the Treatment Center for Children with Cancer (CTCriaC) of the University Hospital of Santa Maria (HUSM). Method: This research has a quantitative approach, which is constituted by a physical evaluation of the areas of free movement of HUSM, as well as space understood by CTCriaC as to the applicability of the Brazilian Regulation: ABNT NBR 9050, and Resolution - RDC n ${ }^{\circ} 50$. Results: The results were presented in statistics and descriptive study that evaluated 266 items, of which only $30.07 \%$ had to be adequate. Among these, $76.92 \%$ of the items corresponding to the external access route are inadequate, and $63.97 \%$ of those related to internal access route to the HUSM CTCriaC and its environment. $80 \%$ and $79.03 \%$ of the corresponding items of the bedrooms CTCriaC and toilets were inadequate, respectively. Conclusion: It was found that evaluated environments were, in most cases, inadequate due to the presence of architectural barriers, which may cause subsequent damage to persons who have reduced mobility for any reason.
\end{abstract}

Keywords: Medical Oncology, Occupational Therapy, Architectural Accessibility, Health Services Accessibility.

Autor para correspondência: Lucielem Chequim da Silva, Coordenação do Curso de Terapia Ocupacional, Universidade Federal de Santa Maria, Avenida Roraima, 1000, Prédio 26C, Sala 4010, Camobi, CEP 97105-900, Santa Maria, RS, Brasil, e-mail: 1chequim@gmail.com

Recebido em Dez. 22, 2016; $1^{\text {a }}$ Revisão em Jul. 26, 2017; 2 ${ }^{\text {a }}$ Revisão em Mar. 13, 2018; Aceito em Jul. 18, 2018.

Este é um artigo publicado em acesso aberto (Open Access) sob a licença Creative Commons Attribution, que permite uso, distribuição e reprodução em qualquer meio, sem restrições desde que o trabalho original seja corretamente citado. 


\section{Introdução}

O câncer é uma condição patológica que se caracteriza pelo crescimento e disseminação desordenados de células anormais devido a alteraçôes no DNA, apresentando capacidade de atingir várias partes do corpo humano quando percorrem a corrente sanguínea e o sistema linfático (STONE, 2011). De acordo com o Instituto Nacional de Câncer (2015), a doença pode surgir a partir da exposição a fatores externos, internos ou a ambos, os quais podem ser pontuados, favorecendo comportamentos relacionados à prevenção do seu desenvolvimento.

Apesar do tratamento ser oferecido através de políticas que preveem e assegurem o cuidado integral do sujeito, o processo que se estabelece desde o diagnóstico até a sua cura, ou melhora na qualidade de vida remanescente, pode ser altamente desgastante e desafiador. Fato que pode ser compreendido devido o câncer ser uma doença de caráter grave e crônico, que exige formas de tratamento bastante invasivas, contribuindo para que os pacientes apresentem prejuízos em sua saúde, referentes aos aspectos psíquicos, sociais e físicos (OTHERO, 2010). Com isso, as pessoas acometidas por esta patologia podem apresentar mobilidade reduzida, passageira ou permanente, devido às consequências inerentes da doença e/ou tratamento (OTHERO, 2010).

Uma variedade de sintomas pode ser apresentada pelos pacientes, incluindo a dor e a diminuição das capacidades físicas, entre outras manifestaçóes decorrentes do tratamento, tornando-se empecilhos para que o mesmo consiga continuar realizando com autonomia e independência suas tarefas anteriores (OTHERO; PALM, 2010). As visitas realizadas pelos pacientes aos serviços de saúde se tornam constantes, suas atividades laborais e sociais podem sofrer transformaçóes, assim como projetos antigos de vida devem ser repensados, e novos surgiráo (OTHERO, 2008). É nessa esfera que os cuidados se mostram importantes, não apenas para a restauração da saúde física, mas também, e não menos necessários, para os aspectos psíquicos e sociais do sujeito.

Considerando que esses sujeitos sofrerão alteraçôes importantes no cotidiano, compreende-se que o desempenho ocupacional possa apresentar, também, prejuízos significativos. Esse refere-se à capacidade da pessoa em realizar suas açóes rotineiras e desempenhar papéis e tarefas nas áreas do autocuidado, produtividade e lazer, as quais estão estritamente relacionadas às necessidades apresentadas pelo homem devido às demandas do seu contexto (AMERICAN..., 2015; CALDAS; FACUNDES; SILVA, 2011). Nessa perspectiva, o tema da acessibilidade revela-se fundamental no que diz respeito à melhoria da qualidade de vida destes e de outros sujeitos que, por diversos motivos, apresentem mobilidade reduzida, aplicando-se, inclusive, em ambientes hospitalares.

A terapia ocupacional se apresenta, portanto, às suas diversas áreas de atuação como uma profissão de conhecimento e intervençáo em saúde, que tem a atividade humana como objeto principal de estudo, utilizando-a como recurso terapêutico, junto com outras tecnologias, para promover ou resgatar a autonomia e independência dos sujeitos, que, por diversos motivos, apresentam limitações de ordem física, mental e/ou social, temporariamente ou não (OTHERO; PALM, 2010). Assim compreende-se que a atuação da terapia ocupacional em oncologia, com ênfase no contexto hospitalar, é de suma importância para que os sujeitos tenham condições físicas e emocionais para enfrentar a situação em que se encontram.

A avaliação terapêutica ocupacional é singular, porém, como afirma Palm (2007), os objetivos básicos do tratamento são:

Intervir no ambiente hospitalar, ambulatorial e domiciliar de modo a melhorar a qualidade de vida nesse período e durante todo o tratamento; proporcionar ao paciente condiçóes para expressar seus temores e percepções, suas condições reais e projeto de vida; identificar, manter ou desenvolver gradativamente a capacidade funcional; favorecer os interesses normais, os contatos sociais e valorizar as potencialidades do paciente (PALM, 2007, p. 490).

Frente a essas possibilidades de intervenção, o terapeuta ocupacional busca conhecer, através de avaliaçôes, quais são as atividades mais significativas para o paciente e construir, a partir da análise do caso, estratégias para sua atuação. Isto é enfatizado, ainda, por Othero (2010), a qual acredita que a atuação deste profissional no âmbito hospitalar destaca-se pelo foco na independência e autonomia. $\mathrm{E}$, enfim, verifica-se que quaisquer tipos de barreiras concretas, ou não, são obstáculos importantes para a realização das tarefas diárias em pessoas com mobilidade reduzida.

Nesse contexto, é importante destacar que, não apenas em locais como a casa, o trabalho, as vias públicas e a escola, por exemplo, devem se mostrar acessíveis àqueles sujeitos com mobilidade reduzida. É necessário que isso se faça presente em edifícios hospitalares, pois é neste ambiente, mais do que em qualquer outro, que sempre haverá indivíduos 
fragilizados e, consequentemente, com suas habilidades físicas suprimidas.

Pela Associação Brasileira de Normas Técnicas (ABNT), NBR 9050, acessibilidade significa a

possibilidade e condição de alcance, percepção e entendimento para a utilização com segurança e autonomia de edificaçôes, espaço, mobiliário, equipamento urbano e elementos (ASSOCIAÇÃO..., 2004, p. 2),

sendo que acessível é qualquer

[...] espaço, edificação, mobiliário, equipamento urbano ou elemento que possa ser alcançado, acionado, utilizado e vivenciado por qualquer pessoa, inclusive aquelas com mobilidade reduzida (ASSOCIAÇÃO..., 2004, p. 2).

Portanto, compreende-se como acessibilidade hospitalar: locais onde todos que circulam, inclusive os pacientes, possam ter o máximo de independência e autonomia que lhes convém.

É fundamental salientar que nem todos os profissionais que atuam nos serviços de saúde têm o conhecimento de que o ambiente e seus fatores podem influenciar nas atividades realizadas pelo homem, atribuindo ao seu quadro clínico as inabilidades apresentadas pelo sujeito (RIGBY et al., 2011). Sobre isso, Rigby et al. (2011, p. 833) discorrem que "a incapacidade pode ser compreendida como ausência de ajustamento entre a pessoa (P), o ambiente (A) e as ocupaçôes diárias $(\mathrm{O})$ da pessoa". Portanto, compreende-se que não é apenas por um quadro patológico que o indivíduo tem o desenvolvimento das suas tarefas comprometidas, mas também por uma lacuna que está entre o homem, as atividades que este realiza e as condiçóes oferecidas pelo ambiente.

Entre os fatores oferecidos pelo meio construído ou natural estão as barreiras e os facilitadores. Entende-se por barreira qualquer característica que dificulte ou impeça a realização das atividades de um sujeito com limitaçóes, as quais podem ser eliminadas ou ajustadas; já os facilitadores, são os aspectos do meio que favoreçam a execução do desempenho ocupacional adequado do ser humano (COOPER et al., 2008).

Com isso, pode-se pensar em melhorar a acessibilidade de diversos locais, inclusive em edifícios hospitalares. Para tanto, devem ser aplicados projetos referentes ao design universal, ou seja, aqueles que têm por objetivo suprir as demandas da maioria dos indivíduos, se não de todos, assim como os projetos sem barreiras, no qual as características que desfavoreceriam o desempenho ocupacional de determinada população seriam removidas (COOPER et al., 2008).

O terapeuta ocupacional estabelece sua prática considerando o ambiente em todas as suas dimensôes físicas, sociais, culturais, organizacionais e institucionais, com pleno conhecimento sobre a influência exercida pelo mesmo no desempenho ocupacional das pessoas, estando apto a realizar análises para aprimorar as habilidades humanas (COOPER et al., 2008; RIGBY et al., 2011). A avaliação terapêutica ocupacional dos ambientes físicos em relação ao desempenho da atividade humana segue um processo pelo qual são inicialmente identificadas as tarefas mais importantes e valorizadas pelo sujeito e posterior análise da performance destas, para, entấo, pressupor qual o nível de ajustamento existente entre o espaço, o homem e suas ocupaçóes (RIGBY et al., 2011).

Nessa perspectiva, identificar as condições de acessibilidade em um Centro de Tratamento da Criança com Câncer de um hospital por profissionais de terapia ocupacional tem significado relevante. É nesse ambiente que muitos pacientes, após o diagnóstico, poderão permanecer em regime de internação, inclusive por longos períodos de tempo, tendo que realizar, diariamente, suas atividades. Por isso, caso o hospital não ofereça as condições necessárias de acessibilidade para os sujeitos, a fim de que desenvolvam suas tarefas com o máximo de autonomia e independência, esses podem apresentar prejuízos ainda maiores no que diz respeito a sua esfera de saúde biopsicossocial.

Portanto, fica explícito que a precarização das condiçôes de acessibilidade pode prejudicar e até impossibilitar a realização das atividades diárias por indivíduos fisicamente debilitados. Desta forma, o presente artigo visa identificar qual o real cenário de acessibilidade física para os usuários no Centro de Tratamento da Criança com Câncer (CTCriaC) do Hospital Universitário de Santa Maria (HUSM).

\section{Método}

Utilizou-se abordagem quantitativa, pois a pesquisa busca compreender de forma estatística os impasses causadores da questão problema, descrevendo as características a serem analisadas com maior precisão. A partir dessa forma de abordagem, é possível esmiuçar a complexidade de um determinado problema e analisar as suas variáveis de forma mensurável, evitando possíveis contradições (PRODANOV; FREITAS, 2013). Foram considerados aspectos materiais e físicos, 
passíveis de serem pontuados e, portanto, avaliados objetivamente, tornando a abordagem quantitativa apropriada para o presente estudo.

Aplicou-se neste trabalho a metodologia descritiva, a qual tem o propósito de observar, analisar e registrar os fatos a serem pesquisados para posterior interpretação, sem que haja interferência do investigador (PRODANOV; FREITAS, 2013). Esse tipo de metodologia ajustou-se às problemáticas e aos objetivos estabelecidos, considerando ainda que, para a coleta dos dados, geralmente são utilizadas técnicas padronizadas como observação e questionário (CASTILHO; BORGES; PEREIRA, 2014).

A técnica de coleta dos dados foi constituída por uma avaliação física de áreas de livre circulação do HUSM (rota externa e interna), assim como do espaço compreendido pelo CTCriaC (áreas de circulação, quartos e sanitários), quanto à aplicabilidade da Norma Brasileira: ABNT NBR 9050 - Acessibilidade a edificações, mobiliário, espaços e equipamentos urbanos (ASSOCIAÇÃO..., 2004) e da Resoluçáo - RDC no 50, de 21 de fevereiro de 2002 (BRASIL, 2002). Salienta-se que foi estipulado um caminho comum aos usuários do serviço, por este ser considerado o principal, estando as áreas de livre circulação compreendidas por esta rota, mas sem levar em consideraçáo outros caminhos secundários.

A partir da leitura intensa e detalhada de ambos os documentos, foram estabelecidos os itens mais importantes a serem avaliados em ambiente hospitalar, os quais foram distribuídos em quatro grupos, compondo um checklist de avaliação física para amostra correspondente a pesquisa (em Anexo A) que contempla as prerrogativas dos documentos analisados. Cada item da lista avaliado possibilitou como resultados: "Existente" e "Inexistente", sendo que "Existente" subdivide-se em "adequado" (quando o espaço físico estava de acordo com as normas), e "inadequado" (quando o espaço físico estava em desacordo às normas para aquele item). Foram consideradas, também, as quantidades de tais itens, quando existentes, a fim de mensurar o percentual de acessibilidade do local.

A presente pesquisa teve apreciação do HUSM, através da Comissão Científica da Gerência de Ensino e Pesquisa (GEP), assim como obteve número de registro 040946 pelo Gabinete de Projetos (GAP) do Centro de Ciências da Saúde da UFSM. A coleta de informaçóes ocorreu entre os meses de agosto e dezembro de 2015. Os dados foram analisados e inseridos no programa Microsoft Office Excel 2010 e apresentados de forma estatística, contendo o enunciado e o número de itens avaliados, assim como a porcentagem em relação às respostas obtidas (inexistente, existente, adequado e inadequado). Também se realizou um estudo teórico, para estabelecer relaçôes com os resultados gerados pela coleta.

\section{Resultados e Discussões}

Os resultados da presente pesquisa encontram-se exemplificados pelas Tabelas 1-4. Estas fazem referência ao tipo de item avaliado, sua quantidade e às condiçóes apresentadas pelo mesmo frente a sua acessibilidade. Os resultados abrangem a rota de acesso externa do HUSM (Tabela 1), assim como a rota de acesso interna do edifício ao CTCriaC e o ambiente do mesmo (Tabela 2), as quais são consideradas dentro dos limites do hospital, tendo como base um único percurso realizado através da entrada principal. Ainda são apresentadas pela tabela 3 e tabela 4 , respectivamente, as condiçóes dos quartos e dos sanitários do CTCriaC.

Foram analisados 266 itens, dos quais $80(30,07 \%)$ apresentavam-se adequados e 186 (69,92\%) inadequados, em relação às normas ABNT-NBR 9050 (ASSOCIAÇÃO...., 2004) e a Resolução - RDC no 50, de 21 de fevereiro de 2002 (BRASIL, 2002). Salienta-se que cada item apenas foi considerado

Tabela 1. Rota de acesso externo do Hospital Universitário de Santa Maria (HUSM).

\begin{tabular}{|c|c|c|c|c|}
\hline \multirow[b]{2}{*}{ Item } & \multirow[b]{2}{*}{ Inexistente } & \multicolumn{3}{|c|}{ Existente } \\
\hline & & $\begin{array}{c}\mathbf{N}^{\circ} \text { de Itens } \\
\text { Avaliados }\end{array}$ & $\begin{array}{c}\text { Adequado } \mathrm{n}^{\circ} \\
(\%)\end{array}$ & $\begin{array}{c}\text { Inadequado } \mathrm{n}^{\circ} \\
(\%)\end{array}$ \\
\hline Estacionamento & $\mathrm{X}$ & - & - & - \\
\hline Calçadas & & 8 & $0(0)$ & $8(100)$ \\
\hline Faixa de travessia de pedestres & & 1 & $1(100)$ & $0(0)$ \\
\hline Rampas & & 2 & $0(0)$ & $2(100)$ \\
\hline Degraus isolados & $\mathrm{X}$ & - & - & - \\
\hline Portas de acesso ao edifício & & 2 & $2(100)$ & $0(0)$ \\
\hline Total & & 13 & $3(23,07)$ & $10(76,92)$ \\
\hline
\end{tabular}

$\mathrm{N}^{\circ} / \mathrm{n}^{\mathrm{o}}$ - número absoluto. Fonte: Autoras. 
acessível quando dispunha de todas as características apontadas pelo referencial bibliográfico base do formulário, sendo avaliado como inadequado quando não se apresentava totalmente acessível.

Desta maneira, a partir da Tabela 1 , evidencia-se a inexistência de estacionamento para os usuários, considerando que há vagas restritas apenas aos servidores, náo contemplando aos interesses da pesquisa. Também não foram encontrados degraus isolados até a porta principal do edifício. Os itens calçadas e rampas encontram-se inadequados, pois estáo em desacordo com as normas em algumas características, como por exemplo, superfície e medidas (ASSOCIAÇÃO..., 2004); sendo que os únicos itens totalmente acessíveis em relação às Normas da Associação Brasileira de Normas Técnicas (2004) se referem à faixa de travessia de pedestres, a qual liga a calçada próxima à via pública com aquela que leva à entrada principal e as portas de acesso.

Tabela 2. Rota de acesso interna do Hospital Universitário de Santa Maria (HUSM) ao Centro de Tratamento da Criança com Câncer (CTCriaC) e ambiente do mesmo.

\begin{tabular}{|c|c|c|c|c|}
\hline \multirow[b]{2}{*}{ Item } & \multirow[b]{2}{*}{ Inexistente } & \multicolumn{3}{|c|}{ Existente } \\
\hline & & $\begin{array}{c}\mathbf{N}^{\circ} \text { de Itens } \\
\text { Avaliados }\end{array}$ & $\begin{array}{c}\text { Adequado } \mathrm{n}^{\circ} \\
(\%)\end{array}$ & $\begin{array}{c}\text { Inadequado } \mathrm{n}^{\circ} \\
(\%)\end{array}$ \\
\hline Corredores & & 9 & $0(0)$ & $9(100)$ \\
\hline Portas & & 3 & $2(66,6)$ & $1(33,3)$ \\
\hline Janelas & & 9 & $3(33,3)$ & $6(66,6)$ \\
\hline Pisos (ambientes) & & 4 & $4(100)$ & $0(0)$ \\
\hline Piso tátil de alerta & $\mathrm{X}$ & - & - & - \\
\hline Piso tátil direcional & $\mathrm{X}$ & - & - & - \\
\hline Desníveis & $\mathrm{X}$ & - & - & - \\
\hline Degraus isolados fixos & $\mathrm{X}$ & - & - & - \\
\hline Escadas fixas & $\mathrm{X}$ & - & - & - \\
\hline Corrimãos & $\mathrm{X}$ & - & - & - \\
\hline Guarda-corpos & $\mathrm{X}$ & - & - & - \\
\hline Elevadores & $\mathrm{X}$ & - & - & - \\
\hline Rotas de fuga & $\mathrm{X}$ & - & - & - \\
\hline Áreas de descanso & & 1 & $1(100)$ & $0(0)$ \\
\hline Rampas & $\mathrm{X}$ & - & - & - \\
\hline Assentos fixos & & 127 & $48(37,8)$ & $79(62,2)$ \\
\hline Balcões & & 3 & $0(0)$ & $3(100)$ \\
\hline Bebedouros & & 2 & $0(0)$ & $2(100)$ \\
\hline Telefones & $\mathrm{X}$ & - & - & - \\
\hline Sinalização de emergência & & 3 & $0(0)$ & $3(100)$ \\
\hline Total & & 161 & $58(36,02)$ & $103(63,97)$ \\
\hline
\end{tabular}

$\mathrm{N}^{\mathrm{o}} \mathrm{n}^{\mathrm{o}}$ - número absoluto. Fonte: Autoras.

Tabela 3. Centro de Tratamento da Criança com Câncer (CTCriaC) - Itens a serem avaliados no interior dos quartos, inclusive em relação ao mobiliário existente.

\begin{tabular}{|c|c|c|c|c|}
\hline \multirow[b]{2}{*}{ Item } & \multirow[b]{2}{*}{ Inexistente } & \multicolumn{3}{|c|}{ Existente } \\
\hline & & $\begin{array}{c}\mathbf{N}^{\circ} \text { de Itens } \\
\text { Avaliados }\end{array}$ & $\begin{array}{c}\text { Adequado } \mathrm{n}^{\circ} \\
(\%)\end{array}$ & $\begin{array}{c}\text { Inadequado } \mathrm{n}^{\circ} \\
(\%)\end{array}$ \\
\hline Portas & & 6 & $0(0)$ & $6(100)$ \\
\hline Janelas & & 18 & $0(0)$ & $18(100)$ \\
\hline Piso (ambientes) & & 6 & $6(100)$ & $0(0)$ \\
\hline Barras de apoio & $\mathrm{X}$ & - & - & - \\
\hline Sinalização de emergência & $\mathrm{X}$ & - & - & - \\
\hline Sinalização tátil & $\mathrm{X}$ & - & - & - \\
\hline Sinalização visual & $\mathrm{X}$ & - & - & - \\
\hline Sinalização sonora & $X$ & - & - & - \\
\hline Total & & 30 & $6(20)$ & $24(80)$ \\
\hline
\end{tabular}

$\mathrm{N}^{\circ} / \mathrm{n}^{\circ}$ - número absoluto. Fonte: Autoras. 
Tabela 4. Centro de Tratamento da Criança com Câncer (CTCriaC) - Sanitários.

\begin{tabular}{|c|c|c|c|c|}
\hline \multirow[b]{2}{*}{ Item } & \multirow[b]{2}{*}{ Inexistente } & \multicolumn{3}{|c|}{ Existente } \\
\hline & & $\begin{array}{l}\mathbf{N}^{\text {o de Itens }} \\
\text { Avaliados }\end{array}$ & $\begin{array}{l}\text { Adequado } \mathrm{n}^{\circ} \\
(\%)\end{array}$ & $\begin{array}{c}\text { Inadequado } \mathrm{n}^{\circ} \\
(\%)\end{array}$ \\
\hline Sanitários acessíveis & $\mathrm{X}$ & - & - & - \\
\hline Portas & & 6 & $0(0)$ & $6(100)$ \\
\hline Piso (ambientes) & & 12 & $6(50)$ & $6(50)$ \\
\hline Barras de apoio & & 2 & $0(0)$ & $2(0)$ \\
\hline Bacia sanitária & & 6 & $0(0)$ & $6(100)$ \\
\hline Boxe para chuveiro ou ducha & & 6 & $0(0)$ & $6(100)$ \\
\hline Lavatório & & 6 & $0(0)$ & $6(100)$ \\
\hline Mictório & $\mathrm{X}$ & - & - & - \\
\hline $\begin{array}{l}\text { Acessórios para sanitários (papeleiras, } \\
\text { saboneteiras e toalheiros) }\end{array}$ & & 18 & $7(38,8)$ & $11(61,1)$ \\
\hline $\begin{array}{l}\text { Dispositivo de segurança para } \\
\text { sanitários acessíveis isolados }\end{array}$ & & 6 & $0(0)$ & $6(100)$ \\
\hline Total & & 62 & $13(20,96)$ & $49(79,03)$ \\
\hline
\end{tabular}

$\mathrm{N}^{\circ} \mathrm{n}^{\mathrm{o}}$ - número absoluto. Fonte: Autoras.

A Tabela 2, referente à rota principal interna de acesso à unidade, assim como as dependências do mesmo, é constituída por vários itens inexistentes, sendo esses: pisos táteis, alerta e direcional; desníveis; degraus isolados fixos; escadas fixas; corrimãos; guarda-corpos; elevadores; rampas e telefones. É importante salientar que a possível presença destes itens por outras rotas secundárias foi desconsiderada, visto que, arquitetonicamente, o local oferece numerosas vias de acesso.

Quanto ao item rotas de fuga, também inexistente, notabiliza-se que, devido à promulgação da Lei 14.376 (RIO GRANDE..., 2013), conhecida como Lei Kiss, as mudanças para readequação estavam sendo providenciadas no momento em que a pesquisa foi realizada. Este decreto estabelece prazos de adequaçóes para as edificaçóes existentes e áreas de risco de incêndio, considerando, inclusive, penalidades ao seu descumprimento.

Sobre os itens existentes, nota-se que todos os corredores estavam inadequados, pois não dispunham de corrimáos ou bate-macas que poderiam ser utilizados como tal, assim como estavam dispostas cadeiras em seu percurso, as quais não são permitidas nos corredores de estabelecimentos assistenciais de saúde (BRASIL, 2002), como também alguns trechos não se apresentavam livres de obstáculos, tendo mobiliários e lixeiras em seu trajeto (ASSOCIAÇÃO..., 2004). Seguindo para o item portas, constatou-se que apenas uma das três avaliadas estava inadequada em relação às normas, devido à presença de maçaneta desapropriada, a qual deveria ser do tipo alavanca para permitir a abertura com apenas um único movimento (ASSOCIAÇÃO..., 2004). Em relação às outras duas portas, essas permaneceram continuamente abertas e com a presença de vigilantes, não apresentado nenhum obstáculo material à passagem dos usuários.

As janelas encontradas nesse percurso foram avaliadas em relação às medidas e características para manuseio, no entanto, ressalta-se que as normas consultadas não estabelecem padrôes exatos de segurança e privacidade, apenas mencionando-os (ASSOCIAÇÃO..., 2004). No local estudado, todas poderiam ser abertas com um único movimento, porém algumas se encontravam inadequadas em relaçấo às medidas.

No caso dos pisos, salienta-se que esses foram considerados separadamente em cada ambiente, nos quais todos se apresentaram adequados, já que a norma prevê uma superfície regular, estável e firme (ASSOCIAÇÃO..., 2004) assim como, com menor número possível de ranhuras (BRASIL, 2002). Sobre o item áreas de descanso, apenas um ambiente como esse foi encontrado no local de estudo e foi considerado adequado por ter dimensões satisfatórias e apresentar cadeiras com encosto, sugeridas pela Associação Brasileira de Normas Técnicas (2004).

Foram encontrados assentos fixos em diversos locais, mencionados na tabela 2 , sendo a maioria considerada inadequada em relação às normas, por localizarem-se em ambiente náo permitido, como corredores, e por náo haver espaço destinado a pessoas usuárias de cadeiras de rodas (ASSOCIAÇĀO..., 2004; BRASIL, 2002). Os itens balcóes e bebedouros apresentaram-se em desacordo com as normas, visto que náo seguiam os padróes estabelecidos de medidas, assim como a sinalização de emergência não abrangia todas as características necessárias de acessibilidade como, por exemplo, alarmes sonoros e 
visuais, e áreas de resgate (ASSOCIAÇÃO..., 2004). Salienta-se que esse último item está correlacionado com as rotas de fuga e, por isso, em fase de adequação às normas.

A partir da Tabela 3, é possível verificar a inexistência de itens fundamentais à acessibilidade, tais como: barras de apoio e sinalização de emergência, tátil, visual e sonora em todo o interior dos seis quartos analisados. No item portas, verifica-se que todas estavam inadequadas, com irregularidades em diversos quesitos, como, por exemplo, na falta de puxadores horizontais exigidos em ambiente hospitalar (ASSOCIAÇÃO..., 2004). Sobre as janelas, foi analisado que todas, apesar de enquadrarem-se nos padrôes de medidas, não permitiam a abertura com apenas um único movimento como é estabelecido na Norma Brasileira NBR 9050 (ASSOCIAÇÃO..., 2004). Os pisos, assim como na tabela anterior, foram analisados de acordo com cada ambiente (quarto), sendo esse o único item da referida tabela que contempla totalmente as normas consideradas pela pesquisa.

Sobre os sanitários de acesso aos usuários presentes no CTCriaC, é possível verificar, através da Tabela 4, que as portas, pisos, barras de apoio, bacias sanitárias, duchas, lavatórios, acessórios e dispositivos de segurança encontram-se inadequados por não contemplarem todas as características de acessibilidade, como, por exemplo, revestimento e medidas. Nota-se ainda a inexistência de sanitários acessíveis e mictórios. $\mathrm{O}$ item pisos encontra-se adequado, no entanto, a área destinada às duchas apresenta desgaste, provavelmente pelo tempo de uso, tornando-se inadequadas ao ambiente hospitalar não apenas por acarretar prejuízos físicos aos usuários, mas também riscos biológicos, considerando que este é um lugar de fácil contaminaçãoo (BRASIL, 2002).

Verificou-se a enorme falta de acessibilidade principalmente nos sanitários do CTCriaC, o que pode acarretar prejuízos significativos aos usuários, principalmente em relação a sua autonomia e independência. Isso pode estar relacionado a aspectos mencionados por Rodrigues (2008, p. 239), o qual destaca que "a adaptação do comportamento e do ambiente favorece a função, quer seja de interaçáo com o ambiente, quer seja de mobilidade". Diante de tal pressuposto, fatores importantes como os mencionados anteriormente podem prejudicar ainda mais o sujeito/usuário em relação não só às suas capacidades físicas, mas também mentais e sociais. Tais consideraçôes são válidas também para os acompanhantes, os quais, apesar de náo serem usuários diretos do serviço, são igualmente influenciados no que diz respeito a si próprio e ao cuidado com o outro.

Salienta-se que um dos quartos, assim como o sanitário correspondente, não foram avaliados, pois encontrava-se em situação de isolamento, devido às condiçóes de saúde do paciente ali internado. Outro fator considerado e verificado no referido hospital, é que a maioria dos móveis presentes nos espaços modificam-se em relação ao tamanho e lugar, de acordo com a demanda de pacientes ou utilização, não apresentando, assim, um mobiliário fiel às normas preconizadas pela Associação Brasileira de Normas Técnicas (2004). Porém, pode-se relevar a hipótese que tal característica beneficia os servidores e também os usuários do local, adequando o ambiente às suas necessidades momentâneas.

As camas hospitalares não foram consideradas nessa pesquisa, apesar de ser um item importante, pois as medidas especificadas na NBR 9050 (ASSOCIAÇÃO..., 2004) não se adequam ao ambiente em estudo. Não foram encontradas outras normas gratuitas e/ou disponíveis para acesso em relação à cama hospitalar.

É imprescindível considerar que, apesar da enorme falta de acessibilidade apontada pela pesquisa em relação ao edifício, o mesmo foi construído na década de 1970 (HOSPITAL..., 2015), época na qual não se direcionava tamanha importância às questôes relacionadas à acessibilidade física das edificaçôes. No entanto, nota-se a dificuldade que seria adaptar todo o ambiente de acordo com as normas vigentes, devido à grande dimensão de uma obra em relação ao tipo de serviço oferecido.

Algumas adaptaçóes realizadas a partir de obras mais recentes foram verificadas e, apesar da tentativa de efetuá-las de acordo com as normas, isso nem sempre foi possível devido a várias características arquitetônicas antigas do local. Dessa forma, reitera-se a importância em verificar as condiçôes físicas da amostra desta pesquisa por terapeutas ocupacionais, os quais relacionam sua prática diretamente ao fazer humano, destacando seus facilitadores e suas barreiras.

Conforme já trabalhado no texto, se uma pessoa está impossibilitada, temporária ou definitivamente, de realizar suas atividades rotineiras de forma independente e eficiente em determinado contexto, poderá ter afetada sua autoestima, horários, finanças, privacidade pessoal e os diferentes papéis que desempenha (MELLO; MANCINI, 2007). E, assim, garantir espaços acessíveis é promover um desempenho ocupacional mais satisfatório. O terapeuta ocupacional atua diretamente nas condiçóes de acessibilidade e utilização de tecnologias com objetivo de favorecer 
a funcionalidade do sujeito, independentemente do contexto que esse se encontra inserido (MARINS; EMMEL, 2011).

Para finalizar a presente discussão, salienta-se a importância de os usuários poderem usufruir de um espaço adequado, o qual potencialize suas capacidades e favoreçam sua autonomia e independência. Dessa maneira a acessibilidade pode colaborar significativamente para a melhora da saúde física, mental e social do sujeito, visto que o mesmo tem pleno direito de realizar suas atividades diárias independente das suas condiçốes de saúde (PAGLIUCA; ARAGÃO; ALMEIDA, 2007).

\section{Conclusão}

A partir da referida pesquisa, confirmou-se a presença de barreiras arquitetônicas nas dependências do HUSM, com consequentes prejuízos às pessoas que apresentam mobilidade reduzida por quaisquer motivos. Essas barreiras constituem-se, principalmente, pela inadequação dos espaços, desde fatores estruturais até ao mobiliário existente no local.

A data de construção do edifício foi considerada como um fator crucial para a falta de acessibilidade física, porém isso não é justificativa para o mesmo permanecer dessa forma, visto que tal situação descumpre a legislação dos direitos humanos. Para tanto, cabe à administração hospitalar atentar-se à legislação vigente, a fim de cumpri-la. Além disso todos os profissionais devem ter consciência acerca da acessibilidade, para saber usufruir significativamente da mesma em prol dos pacientes, visualizando barreiras existentes e solicitando as providências cabíveis.

Destaca-se a importância exercida pelo terapeuta ocupacional no que diz respeito à verificaçáo das condiçôes de acessibilidade física do ambiente hospitalar, pois tal profissional é apto a fazer observaçôes deste cunho, ao possuir conhecimento acerca do fazer humano e, consequentemente, de suas barreiras e facilitadores, sendo capaz de intervir no meio a fim de proporcionar benefícios aos seus usuários.

Dentre as limitaçôes do estudo, observa-se a pouca quantidade de material publicado sobre o referido assunto, independente da área profissional, fazendo-se necessários mais estudos e publicaçóes, o que proporcionará maior visibilidade diante de uma questão atual e de extrema importância. Outro fator a ser mencionado relaciona-se à pequena quantidade de documentos e registros atualizados pelos órgãos responsáveis acerca das condiçôes estruturais da instituição investigada.

\section{Referências}

AMERICAN OCCUPATIONAL THERAPY ASSOCIATION - AOTA. Estrutura da prática da Terapia Ocupacional: domínio \& processo. Revista de Terapia Ocupacional da Universidade de São Paulo, São Paulo, v. 26, p. 1 - 49, 2015. Edição Especial. Disponível em: <http://www.revistas. usp.br/rto/article/view/97496>. Acesso em: 15 dez. 2015.

\section{ASSOCIAÇÃO BRASILEIRA DE NORMAS TÉCNICAS}

- ABNT. NBR 9050: Acessibilidade a edificaçóes, mobiliário, espaços e equipamentos urbanos. Rio de Janeiro: ABNT, 2004.

BRASIL. Resolução RDC no 50, de 21 de fevereiro de 2002. Regulamento técnico para planejamento, programação, elaboração e avaliação de projetos físicos de estabelecimentos assistenciais de saúde. Diário Oficial [da] República Federativa do Brasil, Brasília, DF, 20 maio 2002. Disponível em: <http://www.jusbrasil.com.br/ diarios/485041/pg-39-secao-1-diario-oficial-da-uniaodou-de-20-03-2002>. Acesso em: 22 out. 2015

CALDAS, A. S. C.; FACUNDES, V. L. D.; SILVA, H. J. O uso da Medida Canadense de Desempenho Ocupacional em estudos brasileiros: uma revisão sistemática. Revista de Terapia Ocupacional da Universidade de São Paulo, São Paulo, v. 22, n. 3, p. 238-244, 2011.

CASTILHO, A. P.; BORGES, N. R. M.; PEREIRA, V. T. (Org.). Manual de Metodologia Cientifica. Itumbiara: Iles/ulbra, 2014.

COOPER, B. A. et al. Avaliando o Contexto: Acessibilidade do Lar, Comunidade e Local de Trabalho. In: RADOMSKI, M. V.; TROMBLY, C. A. Terapia Ocupacional para Disfunções Físicas. São Paulo: Santos, 2008. p. 235-253.

HOSPITAL UNIVERSITÁRIO DE SANTA MARIA. Universidade Federal de Santa Maria. Histórico - Apresentação: O HUSM. Santa Maria, 2015. Disponível em: <http:// www.husm.ufsm.br/index.php?janela=historico.html>. Acesso em: 10 nov. 2015.

INSTITUTO NACIONAL DO CÂNCER - INCA. Cancer. Rio de Janeiro, 2015. Disponível em: <http:// www2.inca.gov.br/wps/wcm/connect/inca/portal/homes. Acesso em: 10 maio 2015.

MARINS, S. C. F.; EMMEL, M. L. G. Formação do Terapeuta Ocupacional: Acessibilidade e tecnologias. Cadernos de Terapia Ocupacional da UFSCar, São Carlos, v. 19, n. 1, p. 37-52, 2011.

MELLO, M. A. F.; MANCINI, M. C. Métodos e Técnicas de Avaliação nas Áreas de Desempenho Ocupacional: Avaliação das atividades de vida diária e controle domiciliar. In: GALVÃO, C.; CAVALCANTI, A. Terapia Ocupacional: fundamentação \& prática. Rio de Janeiro: Guanabara Koogan, 2007. p. 49-54.

OTHERO, M. B. Terapia Ocupacional em Oncologia. In: CARVALHO, V. A. et al. (Org.). Temas em Psico-oncologia. São Paulo: Summus, 2008. p. 456-464. 
OTHERO, M. B. Conceitos Gerais em Oncologia. In: OTHERO, M. B. Terapia Ocupacional: Práticas em Oncologia. São Paulo: Roca, 2010. p. 3-15.

OTHERO, M. B.; PALM, R. D. C. M. Terapia Ocupacional em Oncologia. In: OTHERO, M. B. Terapia Ocupacional: Práticas em Oncologia. São Paulo: Roca, 2010. p. 72-110.

PAGLIUCA, L. M. F.; ARAGÃO, A. E. A.; ALMEIDA, P. C. Acessibilidade e deficiência física: identificação de barreiras arquitetônicas em áreas internas de hospitais de Sobral, Ceará. Revista Escola Enfermagem USP, São Paulo, v. 41, n. 4, p. 581-588, 2007.

PALM, R. C. M. Oncologia. In: GALVÃO, C.; CAVALCANTI, A. Terapia Ocupacional: fundamentação \& prática. Rio de Janeiro: Guanabara Koogan, 2007. p. 487-492.

PRODANOV, C. C.; FREITAS, E. C. Metodologia do Trabalho Cientifico: métodos e técnicas da pesquisa e do trabalho acadêmico. Novo Hamburgo: Feevale, 2013.

RIGBY, P. et al. Ambientes Físicos. In: CREPEAU, E. B.; COHN, E. S.; SCHELL, B. A. B. Willard \& Spackman-
Terapia Ocupacional. Rio de Janeiro: Guanabara Koogan, 2011. p. 832-860.

RIO GRANDE DO SUL. Lei complementar n 14376 , de 26 de dezembro de 2013. Estabelece normas sobre Segurança, Prevenção e Proteção contra Incêndios nas edificaçôes e áreas de risco de incêndio no Estado do Rio Grande do Sul e dá outras providências. Diário Oficial do Estado, Rio Grande do Sul, RS, 27 dez. 2013. Disponível em: <http://www.al.rs.gov.br/legis/ M010/M0100099.ASP?Hid_Tipo=TEXTO\&Hid_ Todas Normas=60291 $\&$ hTexto $=\&$ Hid_IDNorma=60291 $>$. Acesso em: 05 nov. 2015.

RODRIGUES, A. C. Reabilitação: prática inclusiva e estratégias para a ação. São Paulo: Andreoli, 2008.

STONE, K. L. Câncer. In: CREPEAU, E. B.; COHN, E. S.; SCHELL, B. A. B. Willard \& Spackman - Terapia Ocupacional. Rio de Janeiro: Guanabara Koogan, 2011. p. 985-988.

\section{Contribuição dos Autores}

Laura Bianchetti Galvan e Andreisi Carbone Anversa foram responsáveis pela concepção do texto manuscrito, organizaçáo de fontes e/ou análises e redação do texto. Alexandra Ramos Moreira da Silva foi responsável pela organização de fontes e/ou análise e revisão do texto. Lucielem Chequim da Silva foi responsável pela concepçáo do texto manuscrito, organização de fontes e/ou análises e revisão. Todos os autores aprovaram a versão final do texto. 
ANEXO A. CHECKLIST DE AVALIAÇÃO FÍSICA PARA AMOSTRA CORRESPONDENTE A PESQUISA: ANÁLISE DE ACESSIBILIDADE NO CENTRO DE TRATAMENTO DA CRIANÇA COM CÂNCER DO HOSPITAL UNIVERSITÁRIO DE SANTA MARIA.

Tabela A1. Rota acessível externa ao Hospital Universitário de Santa Maria (HUSM).

\begin{tabular}{|c|c|c|c|}
\hline \multirow{2}{*}{ ITEM } & \multirow{2}{*}{ INEXISTENTE } & \multicolumn{2}{|c|}{ EXISTENTE } \\
\hline & & ADEQUADO & INADEQUADO \\
\hline Estacionamento & & & \\
\hline Calçadas & & & \\
\hline Faixa de travessia de pedest & & & \\
\hline Rampas & & & \\
\hline Degraus isolados & & & \\
\hline Acessos & & & \\
\hline Portas de acesso ao edifício & & & \\
\hline
\end{tabular}

Tabela A2. Rota acessível interna do Hospital Universitário de Santa Maria (HUSM) ao Centro de Tratamento da Criança com Câncer (CTCriaC) e ambiente do mesmo.

\begin{tabular}{lll} 
& \multirow{2}{*}{ ITEM } & \multicolumn{2}{c}{ EXISTENTE } \\
\hline Corredores & & \\
Acessos & & \\
Portas & & \\
Janelas & & \\
Pisos & & \\
Piso tátil de alerta & \\
Piso tátil direcional & \\
Desníveis & \\
Degraus isolados fixos & \\
Escadas fixas \\
Corrimãos \\
Bate-macas \\
Guarda-corpos \\
Elevadores \\
Rotas de fuga \\
Áreas de descanso \\
Rampas \\
Assentos fixos \\
Balcões \\
Bebedouros \\
Telefones \\
Sinalização de emergência
\end{tabular}

Tabela A3. Centro de Tratamento da Criança com Câncer (CTCriaC) - Itens a serem avaliados no interior dos quartos, inclusive em relação ao mobiliário existente.

\begin{tabular}{lll}
\hline \multicolumn{1}{c}{ ITEM } & \multirow{2}{*}{ INEXISTENTE } & \multicolumn{2}{c}{ EXISTENTE } \\
\cline { 3 - 3 } & & \\
\hline Portas & & \\
Janelas & & \\
Piso & & \\
Barras de apoio & & \\
Áreas de circulação & & \\
Áreas de aproximação & & \\
Áreas de alcance & & \\
Áreas de transferência & & \\
Sinalização de emergência & \\
Sinalização tátil & \\
Sinalização visual & \\
Sinalização sonora &
\end{tabular}


Tabela A4. Centro de Tratamento da Criança com Câncer (CTCriaC) - Sanitários.

\begin{tabular}{lll}
\hline \multicolumn{1}{c}{ ITEM } & \multirow{2}{*}{ INEXISTENTE } & \multicolumn{2}{c}{ EXISTENTE } \\
& & \\
\hline Sanitários acessíveis & & \\
Portas & & \\
Piso & & \\
Barras de apoio & & \\
Bacia sanitária & & \\
Boxe para chuveiro ou ducha & \\
Lavatório & \\
Mictório & \\
Acessórios para sanitários \\
Dispositivo de segurança para sanitários \\
acessíveis isolados \\
Áreas de circulação \\
Áreas de aproximação \\
Áreas de alcance \\
Áreas de transferência
\end{tabular}

